\title{
Poder local, arte urbana e festivalização da cultura
}

Municipalities, Urban Art and the Festivalization of Culture

Pouvoir locale, art urbain et festivalisation de la culture

\section{Ricardo Campos}

\section{OpenEdition}

\section{Journals}

Edição electrónica

URL: https://journals.openedition.org/rccs/12000

DOI: $10.4000 /$ rccs. 12000

ISSN: 2182-7435

\section{Editora}

Centro de Estudos Sociais da Universidade de Coimbra

\section{Edição impressa}

Data de publição: 1 setembro 2021

Paginação: 53-76

ISSN: 0254-1106

\section{Refêrencia eletrónica}

Ricardo Campos, «Poder local, arte urbana e festivalização da cultura», Revista Crítica de Ciências Sociais [Online], 125 | 2021, publicado a 30 setembro 2021, consultado a 03 outubro 2021. URL: http:// journals.openedition.org/rccs/12000 ; DOI: https://doi.org/10.4000/rccs.12000 


\section{RICARDO CAMPOS}

\section{Poder local, arte urbana e festivalização da cultura*}

A arte urbana corresponde a um movimento artístico emergente, que transita entre o espaço mediático, o espaço artístico e o espaço público urbano. A enorme visibilidade e o sucesso que adquiriu nos últimos anos gerou um certo consenso quanto à sua relevância na cidade contemporânea. A arte urbana é, cada vez mais, uma presença assídua na paisagem de diferentes cidades globais. Neste âmbito, as autarquias têm recorrido à arte urbana como ferramenta para alcançarem determinados objectivos, de índole cultural, económica ou turística. A este respeito, um dos dispositivos mais utilizados é o dos festivais de arte urbana, que se inscrevem num processo mais alargado de festivalização da cultura. Neste artigo discutiremos de forma crítica esta questão, partindo de uma revisão extensa da literatura e de dados empíricos recolhidos através de diversos projectos científicos, com particular ênfase na Área Metropolitana de Lisboa.

Palavras-chave: autarquias; desenvolvimento cultural; espaço público; festivais.

\section{Introdução}

O MARCC - Museu de Arte Urbana e Contemporânea de Cascais será um museu dinâmico e inovador localizado no Bairro dos Museus em Cascais, Portugal, centrado em promover o contacto entre o público em geral e o trabalho dos artistas visuais por detrás do movimento global da arte urbana contemporânea, celebrando a energia criativa singular que tem dado novo alento às nossas cidades e redefinido a nossa perceção e fruição da arte. ${ }^{1}$

Comecemos por um breve comentário ao excerto que dá início a este artigo. Esta citação é alusiva ao futuro MARCC, sendo que condensa aquilo que, a nosso ver, são as representações mais frequentemente veiculadas pelo poder público, no que diz respeito à arte urbana. Para além da legitimação

* Por vontade do autor, este artigo não segue as regras do Acordo Ortográfico de 1990.

1 Excerto retirado do website da Câmara Municipal de Cascais. Consultado a 26.02.2021, em https://bairrodosmuseus.cascais.pt/list/museu/museu-de-arte-urbana-e-contemporanea-de-cascais. 
deste movimento artístico por parte de instituições oficiais, que pretendem celebrar a sua "energia criativa singular" procura-se, igualmente, "dar um novo alento à cidade", apadrinhando a arte urbana através de um museu especialmente concebido para o efeito.

A arte urbana, actualmente, parece estar em todo o lado. Esta omnipresença atravessa não apenas a paisagem citadina, mas também o ecossistema mediático e as indústrias culturais. Moda passageira ou a consolidação de uma nova forma de entender a arte no espaço público, facto é que este termo penetrou no discurso público e tornou-se, também, um emblema de políticas urbanas atentas ao potencial que as artes representam para a promoção das cidades e para o seu crescimento económico. Este é um fenómeno relativamente recente, estimulado por um conjunto de entidades e pelos media, pelas indústrias culturais e pela publicidade, que associam estas linguagens estéticas a uma população jovem, urbana, cosmopolita e contemporânea. Banksy, Kobra, Os Gémeos, Shefard Fairey ou os portugueses Vhils, Bordalo II, Mais Menos, Odeith, entre muitos outros, são símbolos de uma geração, mas igualmente a marca de uma nova cidade: global, competitiva, empreendedora, glamorosa e criativa.

Hoje é praticamente consensual a ideia de que a arte urbana é uma mais-valia para as cidades. A esta constatação, soma-se o agrado genérico por parte dos residentes e habitantes, convertidos em público. Ou seja, a quase todos parece contentar esta manifestação artística produzida em espaço público. No entanto, para além das apreciações de índole estética, há considerações de ordem política que têm em conta a posição dos diferentes actores e instituições, bem como os múltiplos impactos resultantes da propagação destas artes. Abordagens mais críticas têm vindo a desvelar consequências inesperadas, associadas ao caminho que estas artes têm percorrido nos últimos anos. Por um lado, desvendam questões relativas à produção do espaço urbano e aos conflitos que daí podem surgir, nomeadamente no que respeita à gentrificação ou turistificação (Andron, 2018; Campos e Sequeira, 2020; Evans, 2016; Young, 2014). Por outro lado, apontam para questões acerca da forma como o poder e as instituições lidam com estas manifestações, o que remete para a sua instrumentalização, institucionalização e mercantilização, mas também para a patrimonialização e preservação deste legado (Campos, 2021; Campos e Barbio, 2021; Pavoni, 2019). Por último, salientam a adulteração a que se tem assistido, com a arte urbana a encaminhar-se num sentido que contradiz o seu espírito original, de índole popular e marginal (Schacter, 2014). Estas questões desvelam dilemas típicos de um campo paradoxal e ambivalente, ainda em construção. 
Uma linha de pesquisa cada vez mais relevante examina a instrumentalização da arte urbana em benefício de determinadas estratégias de desenvolvimento e planeamento urbano (Guinard et al., 2018; Grondeau e Pondaven, 2018; Pavoni, 2019; Raposo, 2019; Salomone, 2018). A arte urbana é hoje um recurso que serve políticas urbanas e culturais, sobretudo no que se refere à requalificação urbana, bem como a estratégias de marketing que visam a divulgação das cidades. Este aproveitamento da arte urbana é também visível no panorama português, sendo notório o crescimento do número de autarquias que têm vindo a realizar os seus próprios projectos nesta área (Campos et al., no prelo; Campos e Barbio, 2021; Carmo et al., 2019; Grondeau e Pondaven, 2018; Pusseti e Barros, 2019; Raposo, 2019).

Neste artigo pretendemos precisamente debater estas questões, partindo, por um lado, de uma revisão da literatura internacional e nacional sobre a temática e, por outro lado, de um conhecimento do meio, que decorre de várias pesquisas realizadas ao longo de uma década, incidindo sobre a Área Metropolitana de Lisboa (AML). Às pesquisas mencionadas, de índole qualitativa (observação etnográfica, entrevistas aprofundadas), devem acrescentar-se diversas formas de colaboração com a Galeria de Arte Urbana da Câmara Municipal de Lisboa. Deste modo, para a reflexão que aqui trazemos, a AML é mobilizada não como estudo de caso, mas servindo para ilustrar e debater algumas das proposições avançadas.

\section{Arte na cidade: instrumento de valorização territorial e de marketing urbano}

A arte e a cultura desempenham um papel relevante na vida nas cidades, facto que dificilmente pode ser negado. Por um lado, a produção cultural, artística e científica sempre esteve associada aos meios urbanos, na medida em que neles encontramos as instituições dedicadas a diferentes formas de saber e arte (os lugares de expressão literária, filosófica, artística, científica). O meio urbano dispõe, então, de recursos materiais e humanos que optimizam a troca e a produção criativa. Por outro lado, as cidades são locais de diversidade cultural, no sentido antropológico do termo. $\mathrm{O}$ volume populacional e a variedade de comunidades beneficiam o contacto com a alteridade e a diferença cultural. Logo, a cidade não é apenas relevante por causa das instituições culturais e artísticas que abriga (universidades, museus, galerias, fundações, etc.), mas também por aquilo que oferece enquanto cenário para o florescimento de variadas formas expressivas.

Deste conjunto de condições muito particulares, surge a cidade enquanto pólo criativo, lugar de heterodoxia, de invenção e inovação cultural. Este é o lugar das artes e culturas oficiais, mas também das artes e culturas informais, marginais e transgressoras (Mould, 2015; Shaw, 2013). Não devemos, 
por isso, estranhar que os movimentos culturais e artísticos mais significativos do último século, mesmo os mais alternativos ou subculturais, tenham emergido em determinados pólos urbanos, com características únicas. É este caldo cultural que torna as cidades singulares, sendo que certos meios urbanos se tornaram planetariamente identificados com os fenómenos artísticos e culturais que aí despontaram. A cena musical de Seattle, o hip-hop e o graffiti nova-iorquinos, o punk de Londres, são apenas alguns exemplos de uma lista interminável. Estas manifestações culturais e artísticas converteram-se em imagens de marca destas cidades que, em muitos casos, fazem um uso estratégico destas referências para processos de city branding.

Neste artigo, a discussão desenrola-se não tanto em torno da natureza destas expressões mais periféricas e idiossincráticas, mas antes em redor da gestão política destas e de outras manifestações de índole estética, cultural e artística na cidade. Ou seja, importa aqui debater como os poderes públicos se relacionam com o campo cultural e artístico e como o entendem do ponto de vista dos seus interesses e fins políticos. Abordar esta problemática através da arte urbana implica, necessariamente, pensar o espaço público e a sua paisagem. Como sabemos, a arte situada no espaço público adquire um papel fundamental na composição das paisagens urbanas, particularmente das grandes cidades. Entramos no campo da denominada arte pública, compreendida aqui no sentido proposto por Miles (1997: 5) enquanto "trabalhos comissionados para locais de acesso público". ${ }^{2}$ Este formato atravessa diferentes épocas históricas e regimes políticos. Importa, precisamente, frisar a natureza política desta arte, pois é promovida pelos regimes e suas instituições de acordo com aquilo que são quadros ideológicos e estéticos historicamente matizados (Balandier, 1999; Short, 1996).

Ao falarmos de poderes públicos e de intervenção na cidade através da arte estamos, claramente, a inscrever um cunho político no processo. Este pode ser entendido em dois sentidos: um primeiro, na medida em que a intervenção, gestão, planificação e regulação do espaço envolve sempre um acto de poder exercido pelas instituições, que definem as estratégias e os mecanismos de desenvolvimento do espaço urbano de acordo com um determinado paradigma; um segundo que remete para a natureza cíclica da transição de poder e para a pluralidade de visões sobre o território que geram dissenso. Deste modo, a arte pública detém sempre esta marca política e, em certo sentido, tem sempre um carácter instrumental.

\footnotetext{
2 Neste sentido, entendemos que o conceito de arte pública é diferente do de arte no espaço público, uma vez que o primeiro implica uma regulação e uma encomenda dirigida por uma entidade (pública ou privada), enquanto o segundo inclui estas manifestações e todas as outras que surgem de modo não regulado no espaço público urbano.
} 
A natureza instrumental da arte pública deriva do facto de esta ser utilizada como um utensílio que visa a prossecução de certos fins, de acordo com uma certa cosmovisão.

É, então, essencial pensar nas artes promovidas pelo poder central e local do ponto de vista do papel instrumental que estas cumprem no quadro de uma certa moldura ideológica e cultural. No contexto que nos ocupa, importa falar das cidades contemporâneas do Norte global, com uma matriz político-económica neoliberal que se tem imposto. A cidade neoliberal é, cada vez mais, gerida de acordo com uma inspiração de natureza empresarial, visando o progresso económico, buscando criar as melhores condições para o florescimento do investimento privado (Estevens, 2017; Mould, 2015). Neste contexto competitivo, a cidade deve promover-se como estratégia de convite ao investimento. Nas últimas três décadas, tem sido especialmente relevante o papel das artes e da cultura como mais-valias para a promoção da imagem das cidades:

Através de investimentos cada vez mais significativos em infraestruturas culturais que se constituem enquanto etiquetas de um design arquitetural, também por via de uma arte pública de grande pendor icónico, ou por intermédio de megaeventos, as economias culturais e as oportunidades e trajetórias de desenvolvimento parecem estar cada vez mais imbricadas. (Duxbury et al., 2012: 5-6)

A cidade criativa converteu-se num chavão que justifica a prossecução de políticas mais ou menos coerentes de investimento nas artes e na cultura (Duxbury et al., 2012; Estevens et al., 2019; Ferreira, 2010; Fortuna, 2010; Guinard e Margier, 2018; Guinard e Molina, 2018; Miles, 2012; Mould, 2015). A ideia subjacente a este modelo é a de que impulsionar o sector criativo (indústrias criativas, clusters criativos, bairros culturais, comunidade artística, eventos culturais e artísticos, etc.) tem repercussões positivas do ponto de vista não apenas simbólico, mas também económico. Este é o paradigma da Cidade Criativa (com "C" maiúsculo) que, segundo Mould (2015), parte de uma visão normalizada, reguladora e instrumental das artes e da cultura percebidas enquanto mais-valias económicas num contexto de crescente competição global. Neste cenário a arte assumiu-se como nova norma do planeamento urbano: "hoje, espaço públicos 'artificados' são um pré-requisito para criar cidades atractivas e competitivas” (Guinard e Margier, 2018: 19). ${ }^{3}$

$\mathrm{Na}$ economia cultural da cidade neoliberal e no ecossistema criativo que se pretende fomentar, há uma dimensão de espectacularidade e de aura que

Todas as traduções são da responsabilidade do autor. 
provém não apenas dos eventos (megaeventos ou festivais de referência), mas também de obras e personagens excepcionais. Deste modo, não podemos ignorar o papel que as celebridades culturais (e o seu glamour) desempenham na actualidade para a divulgação das cidades. Como frisam Currid-Halkett e Scott (2013: 3), "a estrela ou a celebridade funcionam na ordem simbólica como um tipo de fetiche e na ordem económica como um tipo de marca". A natureza aurática e excepcional das estrelas da economia cultural urbana (arquitectos, artistas, músicos, performers, actores, etc.) é transferida para o território. Logo, há um efeito de contágio entre o capital simbólico detido por estas personagens (e pelas suas cenas culturais) e as geografias que habitam ou percorrem. Partindo do caso concreto de Lisboa, podemos referir o exemplo paradigmático do "efeito Madonna", com repercussões evidentes na esfera pública (mediática e política) e com impacto externo não despiciendo. O mesmo se pode afirmar acerca da célebre Web Summit, megaevento internacional famoso pela "fauna de celebridades" (Currid-Halkett e Scott, 2013) que exibe. Ambos são reconhecidos como mais-valias para a cidade de Lisboa, facto que é, aliás, confirmado pelas entidades oficiais que tudo fazem para acarinhar fenómenos similares.

O carácter extraordinário exibido na paisagem citadina revela-se, por exemplo, na arquitectura de autor, presente em edifícios monumentais ou nos murais e esculturas de artistas internacionalmente famosos, bem como em certos arranjos urbanos arrojados e pioneiros. Esta dimensão envolve não apenas celebridades legitimadas pelas diferentes instituições e mundos da cultura (mundo das artes, indústrias culturais, media, etc.), mas também certas cenas culturais alternativas e underground, que conferem um certo glamour às cidades. Vários exemplos poderiam a este respeito ser invocados, mas para o caso em questão, o graffit $i^{4}$ e a arte urbana devem ser salientados como emblemáticos.

\section{A arte urbana e a sua consagração}

Lisboa é já uma cidade reconhecida pela arte urbana e num simples passeio pelo centro ou pelos bairros históricos somos surpreendidos por verdadeiras obras de arte. $^{5}$ (website do Turismo de Portugal "Arte urbana em Lisboa")

\footnotetext{
${ }^{4}$ O termo graffiti é de origem italiana, sendo o plural de graffito, que significa marca ou inscrição realizada numa parede. Neste texto, o termo graffiti é utilizado por referência a uma cultura urbana e uma prática cultural específica e não necessariamente a inscrições produzidas na parede. Neste caso, o termo é utilizado indistintamente no plural ou singular.

5 Consultado a 26.02.2021, em https://www.visitportugal.com/pt-pt/content/arte-urbana-em-lisboa.
} 
$\mathrm{Na}$ sequência do que foi afirmado na secção anterior, podemos concluir que há um enquadramento político-económico, mas também sociocultural, que conduz a uma crescente estetização da cidade (Campos et al., 2011; Guinard e Molina, 2018; Miles, 2012). Tal situação coaduna-se com uma cultura visualista (Campos, 2013) em que a imagem e a visão são dominantes e vão a par com a paulatina estetização e estilização da existência e do quotidiano (Ewen, 1988; Featherstone, 1998; Mirzoeff, 1999). A paisagem urbana espelha toda uma narrativa sobre a cidade que não é descurada e tem sido utilizada pelos poderes públicos, no sentido de tornar os pólos urbanos mais atractivos e dinâmicos. Como afirma Miles (2012: 17), esta é uma cidade da "exibição" em que "o resultado da reabilitação urbana de base cultural tende, portanto, a ser o enobrecimento por meio da estetização e da renovação [...] do edificado". Como sugere o mesmo autor, a estetização do espaço urbano atinge inclusive linguagens e registos culturais de natureza mais transgressiva, como é o caso do graffiti:

Na sua economia simbólica e de marca, até a vida de rua e as disputas do espaço são reacondicionadas - como aconteceu com os grafiti, integrados no mercado de arte. Isto demonstra a função de policiamento brando da cultura, que, em vez de banir uma atividade, a integra numa nova categoria, tornando inofensivo o seu conteúdo. Se os grafiti foram, em tempos, consoante a perspetiva, quer uma voz para os que não têm voz, quer uma praga, hoje em dia são uma mercadoria. (Miles, 2012: 17-18)

O argumento de Miles, que é defendido aliás por outros autores (Banet-Weiser, 2011; Schacter, 2014), conduz-nos então ao tópico do sucesso da arte urbana. O êxito que a arte urbana tem alcançado nos últimos anos, tem de ser interpretado à luz de um paradigma de planeamento urbano em que não apenas a cultura consagrada e as artes canónicas desempenham um papel relevante, mas também, e crescentemente, as expressões culturais mais periféricas e heterodoxas. É precisamente aquilo que sustenta Mould (2015: 21) a propósito da cidade criativa:

[... o neoliberalismo adaptou-se à paisagem em mutação da urbanidade, incluindo a resistência e a subversão. As elites e gestores urbanos estão constantemente procurando o "novo", a nova política ou o artifício inovador de desenvolvimento urbano que pode ser transfigurado para uma nova localidade (com eficiência máxima) para produzir mais riqueza.

A descoberta do potencial da Arte Urbana não é propriamente nova. Como afirma Banet-Weiser, a propósito dos Estados Unidos da América (EUA) no início do milénio, 
O graffiti sancionado e a street art foram vistos recentemente (pelo menos pelos urbanistas) como evidência da singularidade e do carácter de centros urbanos como Nova Iorque, São Francisco, Los Angeles e Filadélfia, tendo sido incorporados como parte da lógica de branding das cidades criativas. (Banet-Weiser, 2011: 647; itálicos do autor)

Estamos, portanto, longe do paradigma do graffiti entendido como deslocado (out of place), socialmente representado como uma anomalia, uma praga urbana e selvagem que convinha a todo o custo combater, como refere Cresswell (1992) a propósito do surgimento deste fenómeno na cidade de Nova Iorque nos anos 1970.

De facto, houve uma gradual reconfiguração do graffiti que permite que actualmente este seja entendido como possuindo um papel a desempenhar na cidade criativa neoliberal. Este foi, todavia, um processo lento. O graffiti que aqui evocamos surgiu em finais da década de 1960 e inícios de 1970 nas cidades de Filadélfia e Nova Iorque, tendo rapidamente alastrado a várias cidades dos EUA (Castleman, 1982; Ferrell, 1996). Em meados dos anos 1980 encontrava-se disseminado por vários meios urbanos fora dos EUA. Mas em que consiste esta forma de graffiti? Podemos distingui-la em função de critérios de diversa ordem. Em termos técnicos, é uma forma de expressão singular que utiliza basicamente marcadores e aerossol para comunicar no espaço público urbano. Em termos sociais, referimo-nos a uma comunidade com um conjunto de valores, práticas e vocabulário próprio, aquilo que pode ser definido como uma subcultura juvenil urbana (Campos, 2010; MacDonald, 2001). Em termos legais, é uma prática transgressiva, não autorizada e ilegal, sendo esta uma marca distintiva clara.

Outro termo recorrente é o de street art, várias vezes utilizado como sinónimo de graffiti. Vejamos o que, a nosso ver, liga e diferencia estes fenómenos. Tal como o graffiti, a street art tem uma base transgressiva, sendo originalmente uma forma de expressão não-autorizada no espaço público (Ross, 2016). Porém, a street art representa uma categoria mais aberta, flexível e socialmente aceitável, estabelecendo pontes com diferentes sectores da sociedade, não apresentando a índole subterrânea e disruptiva do graffiti (Waclawek, 2011; Young, 2014). Do ponto de vista técnico abarca um rol de fórmulas estéticas (stencil, paste-up, sticker, reverse graffiti, escultura, crochet, etc.) inspirando-se em diferentes correntes artísticas.

A natureza mais branda da street art pode explicar o processo de institucionalização que se tem intensificado. Em termos internacionais, é difícil precisar o momento em que este se inicia, todavia há um período marcado por uma série de iniciativas decisivas. Segundo Bengtsen (2014), há a destacar as 
exposições "Barely Legal" de Banksy em Los Angeles (2006), "Street Art" na Tate Modern, em Londres (2008) ou as exposições de Shepard Fairey no Institute of Contemporary Art de Boston e de Banksy no Bristol Museum and Art Gallery (2009). Justifica-se fazer também uma alusão ao primeiro leilão de street art da Bonham, que ocorreu em $2008 .^{6}$

Perante esta diversidade de termos, conceitos e mundos sociais, convém finalmente precisar o que entendemos por arte urbana. A arte urbana faz uma espécie de síntese devidamente filtrada do graffiti e da street art, inspirando-se igualmente num conjunto de referências que derivam quer de movimentos artísticos como a pop-art e o situacionismo, quer das contraculturas urbanas e movimentos de inspiração Do-It-Yourself (Campos e Sequeira, 2018). Este movimento artístico multifacetado opera em várias frentes, não sendo o espaço público urbano o seu terreno exclusivo, ao contrário do que acontecia originalmente com o graffiti e a street art. A arte urbana transita permanentemente entre a rua, a galeria e outros espaços comerciais e institucionais, constituindo-se enquanto movimento com uma identidade eclética, híbrida e, em muitos sentidos, paradoxal. Ao percorrer diferentes patamares simbólicos, corrói hierarquias e fronteiras culturais longamente estabelecidas. Ora se constitui enquanto arte contemporânea com direito a glorificação museológica, ora serve o mercado de massas, sendo utilizada em campanhas publicitárias e na customização de mercadorias diversas.

Neste artigo centramo-nos exclusivamente no domínio da arte urbana enquanto expressão presente no espaço público urbano. A este respeito, podemos certamente afirmar que o sucesso da arte urbana é fabricado à custa de uma regulação da paisagem que mantém uma dualidade de base legal, estética e moral entre as "boas" e as "más" intervenções visuais existentes nas paredes e nos muros das cidades. As estratégias de expansão da arte urbana complementam as acções que, historicamente, visam a invisibilização das inscrições informais indesejadas. Ou seja, as práticas rotuladas como vândalas e poluidoras, nomeadamente o graffiti ilegal, desde que não contenham potencial de valorização estética e simbólica do lugar, ${ }^{7}$ são alvo de demonização e apagamento.

A acção desenvolvida pelos poderes públicos na selecção de artistas e obras é, por si só, uma forma de certificação oficial de determinados agentes

\footnotetext{
6 Mais informações sobre este leilão podem ser consultadas, por exemplo, no website noticioso France 24. Consultado a 27.05.2021, em https://www.france24.com/en/20080205first-auction-dedicated-london-street-art-street-art.

7 Reconhecemos, contudo, alguma ambiguidade relativamente a esta matéria, pois o facto de uma expressão ser ilegal não acarreta automaticamente censura social e acção por parte das autoridades e do poder local. Uma parte substancial do graffiti e da street art que se encontra nas cidades, apesar de ilegal, é socialmente valorizada e tolerada pelos poderes, não sendo alvo de apagamento.
} 
e fórmulas estéticas que se tendem a impor como legítimas. Deste modo, os poderes públicos assumem um papel significativo na forma como se constitui e hierarquiza este campo cultural.

Um dos autores abertamente críticos relativamente a esta dinâmica tem sido Schacter (2014), que denuncia o carácter domesticado e alinhado da arte urbana contemporânea. Para Schacter, a arte urbana é a arte pública da era da cidade criativa, sendo um instrumento que serve para criar, simultaneamente, lugar (tornando os espaços mais atractivos para as classes criativas) e lucro (atraindo investimento):

Essa é uma arte pública que deve contribuir e estar alinhada com as políticas públicas, que deve servir de apoio ao invés de criticar o seu ambiente. [...] É uma arte que funciona como parte integrante de um processo burocrático mais amplo, a arte ao serviço da gestão política profissional. (Schacter, 2014: 164)

Concluímos, então, que a arte urbana é actualmente um mundo da arte legitimado, com direito a estar presente de forma cada vez mais visível, não apenas no espaço público, mas também em instituições artísticas, como galerias e museus. Paralelamente, não podemos ignorar a particular atenção que os media devotam a uma nova geração de artistas pertencendo a este mundo, que se afirmam como figuras altamente mediatizadas. Estas dinâmicas confirmam o processo de consagração da arte urbana.

\section{Poder local e festivais de arte urbana: o caso da AML}

Se a arte urbana pode ser considerada um mundo da arte emergente ${ }^{8}$ (Campos e Leal, 2021; Campos e Sequeira, 2018), a sua promoção por parte do poder local é, também um fenómeno razoavelmente recente. Podemos mesmo afirmar que a construção deste campo não se faz sem uma participação activa do poder local. Nesta secção, recorro a alguns dados de um projecto desenvolvido no contexto da AML (2017-2020). Não se pretende aqui ser demasiado exaustivo na análise, uma vez que tal já foi feito noutro âmbito (Campos, 2021; Campos e Barbio, 2021; Campos e Sequeira, 2018, 2020). Os exemplos trazidos à discussão servem, somente, como elementos ilustrativos que procuram elucidar algumas ideias.

Defendi, logo no início deste texto, que a imagem positiva da arte urbana é, em geral, partilhada pelos poderes, mas também pelos residentes nas cidades. Isto decorre da ideia genérica de que a arte é intrinsecamente

\footnotetext{
8 Empregamos aqui o termo "mundo da arte" no sentido de Becker (1982), em consonância com o argumento de Bengtsen (2014) que entende que a street art é um mundo da arte em construção.
} 
benéfica, por conseguinte a arte pública e os eventos culturais beneficiam a cidade e os seus habitantes. Esta situação pode ser facilmente constatada pelo recurso aos canais de informação das autarquias. Ao examinar os discursos oficiais e as plataformas de comunicação dos municípios que realizam acções neste campo, destaca-se a apologia da arte urbana. ${ }^{9}$ Sobressai, igualmente, a par desta celebração, uma forte associação entre esta expressão e um conjunto de ideias que geralmente orbitam em torno da cidade criativa. Atentemos nas palavras dos autarcas de Cascais, a propósito do anteriormente referido MARCC: ${ }^{10}$

\begin{abstract}
"O nosso desenvolvimento enquanto sociedade passa por criar em Cascais uma comunidade criativa e talentosa, apostando naqueles que já são os nossos maiores criativos", referiu Carlos Carreiras, presidente da Câmara Municipal de Cascais [...] "Depois de termos a Paula Rego, como grande representante da arte contemporânea, tínhamos que ir buscar o Vhils que é aquele que entendemos ser o símbolo de uma juventude muito criativa e altamente cosmopolita, capaz de atrair para Portugal o melhor talento mundial”, afirmou, ainda, Miguel Pinto Luz, vice-presidente da Câmara de Cascais. ${ }^{11}$
\end{abstract}

O sucesso da arte urbana junto dos municípios parece estar assente num conjunto de pressupostos. De um modo geral, a arte urbana é tida como uma manifestação popular, democrática e acessível, que contrasta com as artes canónicas, mais elitistas e herméticas. Daí esta aptidão que transporta para estabelecer um vínculo com o comum dos cidadãos. Daí, também, a sua enorme capacidade para, aparentemente, gerar consensos. Acresce todo um conjunto de representações que endereça a uma certa cultura e linguagem das margens culturais. E temos, então, uma amálgama simbólica que justapõe o decorativismo urbano ao temperamento democrático, acessível e confortável, mas com uma pitada de rebeldia, que gera uma certa unanimidade em torno das suas mais-valias para promover uma cidade mais cool e colorida, cosmopolita, vibrante e criativa.

\footnotetext{
9 Foi feita uma pesquisa envolvendo os websites e documentação oficial produzidos por diversas autarquias da AML.

10 O caso de Cascais é singular, pois o MARCC é o único museu com esta valência em Portugal. De referir, todavia, que este museu anunciado em 2017 não tem data de abertura prevista, uma vez que a Câmara Municipal de Cascais está a procurar uma nova localização para a sua implantação. Noutros países têm despontado, nos últimos anos, diversos museus temáticos dedicados a este movimento artístico: The Museum for Graffiti and Street Art - STRAAT, Street Art Museum Amsterdam - SAMA (ambos em Amesterdão), Museum of Graffiti (Miami), The Street Museum of Art - SMoA, Urban Nation (ambos em Berlim), Street Art Museum - SAM (São Petersburgo). 11 Informação disponível no website da Câmara Municipal de Cascais (2019), "Cascais no centro mundial da Arte Urbana e Contemporânea", Cascais.pt, 12 de Agosto. Consultado a 27.05.2021, em https://www.cascais.pt/noticia/cascais-no-centro-mundial-da-arte-urbana-e-contemporanea.
} 
Partindo dos supostos benefícios da arte urbana, vários são os municípios que lançam empreendimentos especificamente destinados a acolher e a dinamizar esta forma de expressão na paisagem. O caso mais emblemático em que isso acontece é o da Câmara Municipal de Lisboa (CML) que criou em 2008 a Galeria de Arte Urbana, uma estrutura que tem mantido actividade até hoje (Campos e Câmara, 2019; Ferro, 2016; Grondeau e Pondaven, 2018). ${ }^{12}$ Porém, na maioria dos municípios, aquilo que sucede mais frequentemente é um emprego vacilante e episódico da arte urbana por parte das autarquias, em muitos sentidos mimetizando receitas de sucesso.

Como referimos anteriormente, uma das estratégias mais amplamente utilizadas pelos decisores políticos enquadra-se na promoção do evento enquanto elemento de dinamização da arte e da cultura na cidade (Pavoni, 2019). A arte urbana também penetrou neste domínio, como se depreende de iniciativas como a Dismaland, organizada em 2015 por Banksy numa pouco conhecida cidade costeira inglesa (Zebracki, 2018) ou a da realização do maior mural de graffiti do mundo, pelo artista Kobra, no âmbito do processo de regeneração da área urbana que acolheu os jogos olímpicos no Rio de Janeiro. ${ }^{13}$

A arte urbana parece ter-se afirmado como um parceiro importante deste regime da espectacularização e eventificação da cultura que tem como o seu formato de excelência o festival. A festivalização da cultura é uma tendência que se tem vindo a afirmar nos últimos anos (Bennet et al., 2014; Nunes, 2019; Zherdev, 2014), sendo utilizada pelas autarquias como forma de divulgação das cidades, por vezes associando-a à identidade cultural e social e do território. A importância destes eventos para a afirmação dos territórios é de tal ordem que o nome de certas vilas ou cidades de Portugal é, actualmente, indissociável dos festivais que acolhem. Para muitas o reconhecimento internacional deve-se, precisamente, a estas iniciativas. Paulo Nunes (2019:24) condensa a retórica tradicionalmente associada aos festivais urbanos nas seguintes ideias-chave: imagem, turismo e valor económico.

Uma das características frequentemente atribuídas aos festivais artístico-culturais é a do seu regime excepcional. A efemeridade e a efervescência criativa marcam um período determinado na vida da urbe. O festival

\footnotetext{
12 Esta estrutura inserida no Departamento de Património Cultural da CML desenvolve um trabalho sustentado há mais de uma década em prol do desenvolvimento da arte urbana na capital, deste modo procurando também dissuadir a proliferação de expressões de natureza vandálica.

13 A este propósito, o jornal Estadão (Toni, 2016) afirmava o seguinte: "O maior mural de grafite do mundo é carioca, é brasileiro, é nosso. Sensação dos Jogos Olímpicos do Rio, o painel de 2.600 metros quadrados pintado pelo artista Eduardo Kobra na revitalizada zona portuária da Cidade Maravilhosa entrou oficialmente para o Guinness World Records”.
} 
rompe, assim, com o carácter rotineiro da vida urbana, estabelecendo-se como "espaço-tempo de celebração" e de "carnavalização do real" (Nunes, 2019). A excepcionalidade é igualmente fruto do corrupio de celebridades que converte os festivais num espaço de estrelato episódico, que é alvo de peculiar atenção mediática. Se é um facto que tais particularidades também se aplicam a muitos festivais de arte urbana, estes revelam outras características que merecem ser sublinhadas, pois funcionam como um especial atractivo para os poderes municipais. Grande parte dos festivais de arte urbana escapa ao mero impacto efémero, visando um enobrecimento mais consistente do património edificado e do território.

Em suma, podemos afirmar que os festivais de arte urbana correspondem basicamente a cinco grandes objectivos: (a) regulação da paisagem; (b) requalificação material e simbólica do espaço; (c) visibilidade e city branding; (d) promoção da economia; (e) descentralização/democratização cultural. Estes fins cruzam-se e sobrepõem-se. A análise que se fará em seguida está organizada em três grandes objectivos, que agregam os que foram enunciados.

\subsection{Regulação da paisagem e requalificação material e simbólica do espaço}

Actualmente encontramos festivais de arte urbana dispersos por todo o território nacional. ${ }^{14}$ Esta tendência despontou essencialmente na última década, acompanhando a institucionalização e consagração deste movimento artístico. Algumas destas iniciativas são realizadas directamente pelas autarquias, enquanto outras são apenas patrocinadas ou apoiadas por estas. No caso da AML, podemos ressaltar os festivais: Muraliza (Cascais), MURO (Lisboa), Eminente (Oeiras e Lisboa), Loures Arte Pública, Seixal Graffiti, À Babuja - Festival de Street Art do Seixal, Mostra de Graffiti de Almada, Festival Urbano de Almada, Cara ou Coroa Street Art Festival (Setúbal) ou Art in Town (Barreiro).

Uma análise da informação disponível sobre estas iniciativas é bastante elucidativa. No festival À Babuja (2019) procura-se "dar nova vida e cor a alguns locais do núcleo urbano antigo do Seixal" ${ }^{15}$ no Art in Town (2020) visa-se "uma nova imagem e dinâmica contemporânea para a cidade"; 16 no festival MURO (2019) procura-se "a regeneração e valorização do espaço

\footnotetext{
14 De acordo com um inventário que realizámos (2016-2017) a festivais de arte urbana em território nacional, existiam cerca de 20 cidades com eventos desta natureza.

15 Informação disponível no website da Câmara Municipal do Seixal em http://www.cm-seixal.pt/ babuja-festival-de-street-art-do-seixal/2019/babuja-festival-de-street-art-do-seixal-2019. Consultada a 26.02.2021.

16 Informação disponível no website do evento, em https://www.artintown.pt/. Consultada a 26.02.2021.
} 
público e a sua apropriação por parte da população residente", ${ }^{17}$ enquanto a propósito do Muraliza, a agenda de Cascais revela "que as paredes do centro histórico de Cascais ganharam uma nova dimensão". ${ }^{18}$

Destaca-se destes excertos a inclinação para pensar o festival como produzindo efeitos a longo prazo, servindo para mudar a paisagem, mas também a imagem da cidade e a relação dos habitantes com o espaço público. Como referiu um profissional de curadoria entrevistado no âmbito do projecto e que trabalha assiduamente com as autarquias na produção deste tipo de actividades: "existe esta ideia de que é algo que vende bem, e que é bonito, e que estamos a embelezar, e que estamos a decorar a cidade, e o município gosta disso".

Conclui-se, então, que a arte urbana é frequentemente imaginada enquanto dispositivo de construção da paisagem. Esta dimensão está associada ao pressuposto segundo o qual a arte urbana beneficia o território. Deste modo, o simples facto de se executarem obras de arte urbana é entendido como factor de revitalização e regeneração urbana, vinculado a uma lógica eminentemente decorativista. Consequentemente, estes processos contribuem para a requalificação material do espaço urbano, facto que justifica que muitos destes festivais se concentrem em territórios mais fragilizados e desvalorizados. Em articulação com a requalificação material encontramos uma recuperação da imagem do território, uma valorização simbólica que decorre da transformação da paisagem.

Convém, porém, ressaltar que este investimento numa arte urbana regulada se inscreve na óptica das "geografias morais", descrita por McAuliffe (2012). Isto é, a arte urbana acarinhada pelos poderes é aquela que se inscreve num certo consenso estético, no padrão do gosto dominante. Deste modo, pretende-se geralmente atingir um duplo efeito: por um lado, embelezar o espaço público; por outro lado, conter expressões de carácter mais disruptivo, entendidas como comprometedoras da qualidade desse espaço público.

\subsection{Visibilidade e promoção da economia}

À requalificação do território associam-se ideias de promoção da imagem da cidade e, consequentemente, de dinamização económica, particularmente através do turismo. Uma consulta das plataformas de comunicação das autarquias é bastante curiosa, pelo tom apologista relativamente à arte

\footnotetext{
17 Informação disponível no website da Galeria de Arte Urbana, em http://gau.cm-lisboa.pt/muro. html. Consultada a 26.02.2021.

18 Informação disponível na Agenda Cultural de Cascais n. ${ }^{\circ}$ 69. Consultada a 26.02.2021, em https://issuu.com/agendacascais/docs/prova_final_issu.
} 
urbana e pela colagem de algumas autarquias ao sucesso internacional deste movimento. Nessa medida, Cascais não apenas promove o MARCC como, através do festival Muraliza, "mantém o desejo (repetido) de renovação do estatuto de Cascais como berço de todas as expressões artísticas de rua em Portugal". ${ }^{19}$ Já a autarquia de Loures, através do festival Loures Arte Pública, afirma que "a arte urbana é já hoje uma das imagens de marca do concelho de Loures, tendo o seu ponto alto na Galeria de Arte Pública (GAP) do Mocho". 20

A transformação da paisagem com vista a convertê-la num produto de consumo turístico é algo que está muito presente em múltiplas iniciativas das autarquias que, nalguns casos, dão origem a mapas e roteiros de visita. ${ }^{21}$ Algumas pesquisas têm destacado precisamente o potencial desempenhado por estas expressões para o crescimento deste sector da economia (Andron, 2018; Campos e Sequeira, 2020; Miguel-Molina et al., 2013; Mokras-Grabowska, 2014). No caso de Portugal, esta situação é reconhecida ao nível daqueles que gerem a imagem do país no exterior, como admitia em 2015 o presidente do Turismo de Portugal, que afirmava o seguinte: “[...] pelas respostas aos inquéritos que fazemos a arte urbana é já um dos motivos de agrado importantes nas viagens de city breaks e de touring”. ${ }^{22}$ Em consonância com esta visão, num artigo da OJE publicado no website da Assembleia Municipal de Lisboa em 2014, ${ }^{23}$ colocava-se a seguinte questão à responsável da Galeria de Arte Urbana (GAU): "Considera que a arte urbana tem trazido a Lisboa [...] retorno turístico e até um novo posicionamento da cidade: trendy e criativa?". A resposta é elucidativa: "Há vários sinais que nos indicam isso, nomeadamente o facto de as revistas internacionais de turismo que dedicam artigos à cidade de Lisboa mencionarem, frequentemente, a arte urbana como uma mais-valia e como um aspecto a visitar na cidade".

Em estudos mais recentes, esta ideia não apenas está presente como parece ter adquirido ainda maior protagonismo, perante a ascendente relevância do turismo na economia local (Campos e Barbio, 2021; Campos e Sequeira, 2020).

\footnotetext{
19 Website da Câmara Municipal de Cascais, 12 de Agosto 2019. Consultado a 26.02.2021, em https://www.cascais.pt/noticia/muraliza-festival-de-arte-mural-de-cascais.

20 Website da Câmara Municipal de Loures dedicado ao Loures Arte Pública. Consultado a 26.02.2021, em https://www.cm-loures.pt/Media/Microsite/Artepublicaloures/index.html.

21 Autarquias como as da Amadora, do Barreiro, de Loures ou de Lisboa disponibilizam online roteiros de arte urbana na cidade que podem ser visitados e percorridos pelos interessados.

22 "Arte urbana de Lisboa é cada vez mais uma atracção turística", Lusa e Público, 26 de Abril 2015. Consultado a 26.02.2021, em https://www.publico.pt/2015/04/26/local/noticia/ arte-urbana-de-lisboa-e-cada-vez-mais-uma-atraccao-turistica-1693672.

23 "Arte urbana traz retorno turístico a Lisboa", OJE, 17 de Outubro 2014. Consultado a 26.02.2021, em https://www.am-lisboa.pt/101000/1/001140,102014/index.htm.
} 
As palavras de alguns dos nossos entrevistados reforçam precisamente esta ideia, como se pode depreender deste excerto:

Trazer mais pessoas à cidade para poderem ver os murais, também faz com que fiquem e que conheçam a nossa gastronomia. O Barreiro - aquele estigma que existe de vir cá a este lado... Pode ser que aqui se consiga colmatar um bocadinho, muitas vezes, esta ideia que existe de que estamos muito longe, ou de que é uma cidade muito escura ou uma cidade muito feia e podia estar aqui um jardim fantástico. Pronto. E isto depois leva-nos a que mais pessoas venham ao Barreiro, não é? Isso também é um objectivo primordial para nós, Câmara. (Entrevista à vereadora da Juventude da Câmara Municipal do Barreiro, 2018)

\subsection{Descentralização e democratização cultural}

Nalguns casos, os festivais criam novas polaridades culturais e, inclusive, possibilitam uma reconversão da imagem estigmatizada de certos territórios. Dois casos emblemáticos a este respeito são os festivais O Bairro i o Mundo (Loures) e MURO (Lisboa). O primeiro iniciou-se em 2014 na Quinta do Mocho, ${ }^{24}$ considerado um bairro problemático e violento (Raposo, 2019). Uma entrevista realizada ao representante da autarquia é elucidativa relativamente à finalidade desta aposta:

Esta situação na Quinta do Mocho teve o objectivo preciso, em que a Câmara em conjunto com os moradores poder [sic] de facto transformar e produzir um projecto de transformação da imagem negativa que havia do bairro, mas também na transformação e da melhoria das condições de vida das pessoas. Portanto, a arte serviu no início como pretexto para aproximar as pessoas do próprio bairro e das pessoas do próprio bairro com a Câmara. Mas, aos poucos há transformações também numa imagem diferente do próprio bairro, para o exterior, quebrando o estigma que o próprio bairro tinha, nomeadamente negativo, que era um bairro mau, de malandros; de ladrões, que não era possível lá ir, porque toda a gente seria assaltada ou maltratada. (Entrevista à vereadora da Educação, Coesão Social e Habitação da Câmara Municipal de Loures, 2018)

Actualmente o bairro é conhecido por deter uma das maiores galerias de arte pública da Europa, contando com cerca de uma centena de obras de grandes dimensões, pintadas nas fachadas dos prédios. Hoje existem visitas turísticas dinamizadas por residentes do bairro, mas igualmente por empreendedores externos.

${ }_{24}$ Este é um bairro de habitação social, com cerca de três mil residentes, sendo a sua maioria imigrantes de origem africana e seus descendentes. 
A mesma lógica parece presidir ao festival MURO, organizado pela GAU em Lisboa. Um dos objectivos da GAU é o de "criar novas polaridades culturais e criativas na cidade" (Grondeau e Pondaven, 2018). Ora, o festival MURO obedece precisamente a este propósito. Iniciado em 2016, o festival conta com três edições realizadas em bairros diferentes da cidade (Padre Cruz, Marvila e Lumiar). A propósito da primeira edição do festival no bairro Padre Cruz, tido como "o maior bairro social da Europa", uma das representantes da GAU afirmava o seguinte a um órgão de comunicação social:

É um território situado na periferia da cidade e interessava-nos muito trabalhar estas zonas. Por outro lado, a própria configuração arquitetónica do bairro, que se presta muito a acolher as intervenções. Há um conjunto alargadíssimo de edifícios e só há uma peça de arte pública no bairro, um monumento ao Padre Cruz. Era uma forma de enriquecer a nível visual a paisagem deste território. (Inês Machado in Visão, 3 de Maio de 2016) ${ }^{25}$

Deste modo, não apenas os festivais citados, bem como outros que têm vindo a ocorrer, apostam na receita da dispersão territorial da arte urbana, canalizando-a para bairros menos centrais e carenciados, numa lógica de descentralização cultural, mas também de reconversão da imagem do território. Visa-se, assim, a democratização do acesso à arte e à cultura, mas, simultaneamente, um reforço positivo da auto-estima das comunidades. Finalmente, esta valorização do território permite criar novos pólos de atracção cultural, abrindo estes bairros ao exterior.

Para terminar, gostaria apenas de acrescentar que o encerramento da primeira edição do festival MURO contou com a presença do presidente da autarquia, mas igualmente do Presidente da República, ${ }^{26}$ o que é elucidativo da centralidade, normalização e consagração da arte urbana ao mais alto nível institucional. Neste evento dentro do próprio evento, o Presidente da República reforçou o tom geral que se tornou apanágio destas iniciativas:

é uma forma de mostrar que o bairro está vivo, que aponta para o futuro, que está a dar uma volta na parte mais antiga, e de vencer o preconceito de que há bairros de

25 Visão (2016), "Festival de arte urbana invade o bairro Padre Cruz de novas cores", 3 de Maio. Consultado a 26.02.2021, em http://visao.sapo.pt/iniciativas/por-um-bairro-melhor/ 2016-05-03-Festival-de-arte-urbana-invade-o-bairro-Padre-Cruz-de-novas-cores.

26 Esta situação foi aliás noticiada pelo website da Presidência da República Portuguesa (2016), "Presidente da República visitou o Festival de Arte Urbana LX_2016", 14 de Maio. Consultado a 26.02.2021, em http://www.presidencia.pt/?idc=10\&idi=106998. 
primeira, de segunda, de terceira, de quarta, de quinta, de sexta. (Marcelo Rebelo de Sousa in Diário de Notícias, 16 de Maio de 2016) ${ }^{27}$

\section{Conclusão}

O sucesso da arte urbana inscreve-se num paradigma que se disseminou e que tem em consideração o papel das artes, da cultura e da criatividade como motores para o desenvolvimento das cidades. As vantagens apontadas são múltiplas e podem ser entendidas do ponto de vista macro (city branding, incentivo ao turismo, regeneração urbana, democratização do acesso à arte, etc.) ou micro (desenvolvimento de certos territórios, promoção da auto-estima dos residentes dos bairros, participação e empowerment, etc.). Este é o panorama que serve de enquadramento à acção dos municípios relativamente a esta matéria.

A arte urbana pode, então, ser entendida enquanto recurso para a dinamização da cidade criativa. Neste artigo, destaquei aquela que é, talvez, a ferramenta mais frequentemente utilizada no âmbito destas iniciativas. Os festivais de arte urbana, têm sido concretizados pelo país fora como uma receita de sucesso. Estes inscrevem-se numa tendência de festivalização da cultura que remete para a relevância que os (mega)eventos adquirem no âmbito da espectacularização e estetização das cidades. Os festivais de arte urbana estão ligados a um conjunto de imagens que se revelam fulcrais para o branding das cidades contemporâneas: a democratização do acesso à cultura, o empreendedorismo cultural, o cosmopolitismo, o hibridismo cultural ou a vitalidade das culturas urbanas periféricas. Deste modo, o investimento em arte urbana no espaço público é um factor de distinção, não apenas permite criar cidades com recursos artísticos relevantes (murais, empenas pintadas, etc.), mas também dinamiza uma classe criativa/comunidade artística que é um elemento fundamental da identidade da cidade. Como corolário destas iniciativas e da transformação da paisagem, surge o turismo, interno e externo. A turistificação da arte urbana é um fenómeno recente, sendo mesmo considerado uma das principais estratégias de incentivo ao turismo em cidades pós-industriais, sem património histórico de monta.

Para finalizar, convém ressaltar que aquilo que aqui descrevemos é fruto de um processo histórico e cultural longo que se inicia com o surgimento e a disseminação planetária do graffiti urbano. Testemunhámos ao longo de décadas, com especial incidência a partir da transição para o século XXI, um

\footnotetext{
27 Joana Capucho (2016), "Arte urbana mudou a cara do maior bairro social da Europa”, Diário de Notícias, 16 de Maio. Consultado a 26.02.2021, em https://www.dn.pt/sociedade/arte-urbanamudou-a-cara-do-maior-bairro-social-da-europa-5176254.html.
} 
lento processo de institucionalização e mercantilização de um conjunto de manifestações de rua, de índole mais selvagem e popular. Estas foram gradualmente penetrando no mercado da arte, na publicidade, nos media e nas indústrias culturais. Neste trânsito foram perdendo capacidade disruptiva, domesticadas pelo mercado e pelo gosto dominante. Nesta dinâmica e no que respeita propriamente ao território citadino, os poderes públicos também intervêm. Por um lado, legislando sobre, e policiando, as intervenções visuais no espaço público e, por outro, incentivando a proliferação de certos formatos e expressões que são entendidos como um factor de enobrecimento urbano. Deste modo, sobre estas formas de intervenção visual impendem um conjunto de juízos de ordem moral, estética e política que são basilares para a forma como se constrói o mundo da arte urbana contemporânea.

Revisto por Sofia Silva

\section{Referências bibliográficas}

Andron, Sabina (2018), "Selling Streetness as Experience: The Role of Street Art Tours in Branding the Creative City", The Sociological Review, 66(5), 1036-1057.

Balandier, Georges (1999), O poder em cena. Coimbra: Minerva. Tradução de Ana Moreia Lima [ed. orig. 1980]

Banet-Weiser, Sarah (2011), "Convergence on the Street", Cultural Studies, 25(4-5), 641-658.

Becker, Howard (1982), Art Worlds. Los Angeles: University of California Press.

Bengtsen, Peter (2014), The Street Art World. Lund: Almendros de Granada Press.

Bennett, Andy; Taylor, Jodie; Woodward, Ian (orgs.) (2014), The Festivalization of Culture. Ashgate: Surrey and Burlington.

Campos, Ricardo (2010), Porque pintamos a cidade? Uma abordagem etnográfica ao graffiti urbano. Lisboa: Fim de Século.

Campos, Ricardo (2013), Introdução à cultura visual. Abordagens e metodologias em ciências sociais. Lisboa: Mundos Sociais.

Campos, Ricardo (2021), "Urban Art in Lisbon: Opportunities, Tensions and Paradoxes”, Cultural Trends, 30(2), 139-155. DOI: https://doi.org/10.1080/09548 963.2021.1897779

Campos, Ricardo; Abalos Junior, José; Raposo, Otávio (no prelo), “Arte urbana, poderes públicos e desenvolvimento territorial: uma reflexão a partir de três estudos de caso", Etnográfica.

Campos, Ricardo; Barbio, Leda (2021), "Public Strategies for the Promotion of Urban Art. The Lisbon Metropolitan Area Case”, City \& Community, 20(2), 121-140. DOI: https://doi.org/10.1177/1535684121992350 
Campos, Ricardo; Brighenti, Andrea Mubi; Spinelli, Luciano (orgs.) (2011), Uma cidade de imagens. Produção e consumo visual em meio urbano. Lisboa: Mundos Sociais. Campos, Ricardo; Câmara, Silvia (2019), Arte(s) urbana(s). Vila Nova de Famalicão: Húmus.

Campos, Ricardo; Leal, Gabriela (2021), "An Emerging Art World: The De-Subculturalization and Artification Process of Graffiti and Pixação in São Paulo", International Journal of Cultural Studies, maio. DOI: https://doi.org/10.1177/ 13678779211018481

Campos, Ricardo; Sequeira, Ágata (2018), “O mundo da arte urbana emergente: contextos e atores”, Todas as Artes. Revista Luso-Brasileira de Artes e Cultura, 1(2), 70-93. DOI: $10.21747 / 21843805 / \operatorname{tav} 1 \mathrm{n} 2 \mathrm{a} 4$

Campos, Ricardo; Sequeira, Ágata (2020), "Urban Art Touristification: The Case of Lisbon”, Tourist Studies, 20(2), 182-202. DOI: https://doi.org/10.1177/ 1468797619873108

Carmo, André; Matos, Filipe; Pereira, Sónia (2019), "Regeneração urbana através da cultura e das artes : o caso do Barreiro", Forum Sociológico, 35(1), 61-70.

Castleman, Craig (1982), Getting Up - Subway Graffiti in New York. Massachusetts: MIT Press.

Cresswell, Tim (1992), “The Crucial 'Where' of Graffiti: A Geographical Analysis of Reactions to Graffiti in New York”, Environment and Planning D: Society and Space, 10(3), 329-344.

Currid-Halkett, Elizabeth; Scott, Allen (2013), "The Geography of Celebrity and Glamour: Reflections on Economy, Culture, and Desire in the City”, City, Culture and Society, 4, 2-11.

Duxbury, Nancy; Fortuna, Carlos; Bandeirinha, José António; Peixoto, Paulo (2012), "Em torno da cidade criativa", Revista Crítica de Ciências Sociais, 99, 5-8.

Estevens, Ana (2017), A cidade neoliberal. Conflito e arte em Lisboa e Barcelona. Lisboa: Le Monde Diplomatique.

Estevens, Ana; Cocola-Gant, Agustín; Calvo, Daniel Malet; Matos, Filipe (2019), "As artes e a cultura nas práticas hegemónicas e alternativas na cidade de Lisboa. O caso do Largo do Intendente”, Forum Sociológico, 35(1), 9-17.

Evans, Graeme (2016), "Graffiti Art and the City”, in Jeffrey Ian Ross (org.), Routledge Handbook of Graffiti and Street Art. Abingdon, UK: Routledge, 168-182.

Ewen, Stuart (1988), All Consuming Images. The Politics of Style in Contemporary Culture. New York: Basic Books.

Featherstone, Mike (1998), "Postmodernism and the Aestheticization of Everyday Life”, in Scott Lash; Jonathan Friedman (orgs.), Modernity and Identity. Oxford e Cambridge: Blackwell Publishing, 265-290.

Ferreira, Claudino (2010), "Cultura e Regeneração Urbana: novas e velhas agendas da política cultural para as cidades”, Tomo, 16, 29-56. 
Ferrell, Jeff (1996), Crimes of Style. Urban Graffiti and The Politics of Criminality. Boston, Massachussets: Northeastern University Press.

Ferro, Lígia (2016), Da rua para o mundo. Etnografia urbana comparada do graffiti e do parkour. Lisboa: Imprensa de Ciências Sociais.

Fortuna, Carlos (2010), “Novos trilhos para a cultura: Como não falar de cidade?”, in Maria de Lourdes Lima Santos; José Machado Pais (orgs.), Trilhos para a cultura: práticas e políticas. Lisboa: ICS, 273-280.

Grondeau, Alexandre; Pondaven, Florence (2018), "Le street art, outil de valorisation territoriale et touristique: l'exemple de la Galeria de Arte Urbana de Lisbonne", EchoGéo, 44. Consultado a 14.02.2019, em http://journals.openedition.org/ echogeo/15324.

Guinard, Pauline; Jacquot, Sébastien; Kullmann, Clotilde (2018), "Les valorisations territoriales et touristiques du street art", EchoGéo, 44. Consultado a 23.04.2020, em http://journals.openedition.org/echogeo/15624.

Guinard, Pauline; Margier, Antonin (2018), “Art as a New Urban Norm: Between Normalization of the City Through Art and Normalization of Art Through the City in Montreal and Johannesburg", Cities, 77, 13-20.

Guinard, Pauline; Molina, Géraldine (2018), "Urban Geography of Arts: The Co-Production of Arts and Cities”, Cities, 77, 1-3.

Macdonald, Nancy (2001), The Graffiti Subculture: Youth, Masculinity and Identity in London and New York. New York: Palgrave Macmillan.

McAuliffe, Cameron (2012), "Graffiti or Street Art? Negotiating the Moral Geographies of the Creative City”, Journal of Urban Affairs, 34(2), 189-206.

Miguel-Molina, María de; Santamarina-Campos, Virginia; Miguel-Molina, Blanca de; Segarra-Oña, María del Val (2013), "Creative Cities and Sustainable Development: Mural-Based Tourism as a Local Public Strategy", Dirección y Organización, 50, 31-36.

Miles, Malcom (2012), "Uma cidade pós-criativa?”, Revista Crítica de Ciências Sociais, 99, 9-30. Consultado a 01.05.2019, em https://journals.openedition.org/rccs/5091. Tradução de Isabel Donas Botto.

Miles, Malcolm (1997), Art, Space and the City - Public Art and Urban Futures. London: Routledge.

Mirzoeff, Nicholas (1999), An Introduction to Visual Culture. London/New York: Routledge.

Mokras-Grabowska, Justyna (2014), “Art-Tourism Space in Lodz: The Example of the Urban Forms Gallery”, Tourism, 24(2), 23-30.

Molnár, Virág (2018), "The Business of Urban Coolness: Emerging Markets for Street Art”, Poetics, 71, 43-54.

Mould, Oli (2015), Urban Subversion and the Creative City. London/New York: Routledge. 
Nunes, Paulo (2019), "Retóricas conjugadas: festivais culturais, cidades e modos de vida urbanos", CSOnline - Revista Eletrônica de Ciências Sociais, 29, 18-31. Consultado a 28.07.2021, em https://periodicos.ufjf.br/index.php/csonline/article/view/26399.

Pavoni, Andrea (2019), "Speculating on (the) Urban (of) Art: (un)Siting Street Art in the Age of Neoliberal Urbanisation”; Horizontes Antropológicos, 25(55), 51-88.

Pussetti, Chiara; Barros, Vitor (2019), "O terceiro lado do muro. A arte e as suas cidades”, Forum Sociológico, 35, 51-59.

Raposo, Otávio (2019), “The Reinvention of a Peripheral Neighborhood in Lisbon: Reflections on Urban Art, Ethnography and Public Policy”, in Lígia Ferro; David Poveda (orgs.), Arts and Ethnography in a Contemporary World: From Learning to Social Participation. London: Tufnell Press.

Ross, Jeffrey (2016), Routledge Handbook of Graffiti and Street Art. London/New York: Routledge.

Salomone, Christine (2018), "Le street art à Naples”, EchoGéo, 44. Consultado a 23.04.2020, em http://journals.openedition.org/echogeo/15640.

Schacter, Rafael (2014), “The Ugly Truth: Street Art, Graffiti and the Creative City”, Art \& the Public Spbere, 3(2), 161-176.

Shaw, Kate (2013), "Independent Creative Subcultures and Why They Matter", International Journal of Cultural Policy, 19(3), 333-352.

Short, John (1996), The Urban Order. Massachusetts: Blackwell.

Toni, Bruna (2016), "Sucesso durante a Olimpíada, mural de Kobra no Rio entra para o Guinness Book”, Estadão, 24 de agosto. Consultado a 30.07.2021, em https://viagem.estadao.com.br/blogs/viagem/sucesso-durante-a-olimpiadamural-de-kobra-no-rio-entra-para-o-guinness-book/.

Waclawek, Anna (2011), Graffiti and Street Art. London: Thames \& Hudson.

Young, Alison (2014), Street Art, Public City: Law, Crime and the Urban Imagination. London/New York: Routledge.

Zebracki, Martin (2018), "Regenerating a Coastal Town Through Art: Dismaland and The (L)Imitations of Antagonistic Art Practice in the City", Cities, 77, 21-32.

Zherdev, Nikolay (2014), "Festivalization as a Creative City Strategy", IN3 Working Paper Series. Consultado a 30.07.2021, em https://cercles.diba.cat/documentsdigitals/ pdf/E140137.pdf. 


\section{Ricardo Campos}

Centro Interdisciplinar de Ciências Sociais (CICS.NOVA - NOVA FCSH)

Colégio Almada Negreiros, Campus de Campolide, 3. ${ }^{\circ}$ piso - Sala 333, 1070-312 Lisboa, Portugal

Contacto: ricardocampos@fcsh.unl.pt

ORCID: https://orcid.org/0000-0003-4689-0144

Artigo recebido a 06.05.2020

Aprovado para publicação a 24.06.2021

https://doi.org/10.4000/rccs. 12000

\section{Municipalities, Urban Art and the Festivalization of Culture}

Urban art corresponds to an emerging artistic movement, which transits between the media space, the artistic space and the urban public space. The enormous visibility and success it has acquired in recent years, has generated a certain consensus as to its relevance in the contemporary city. Urban art has increasingly become an ever-present feature on the landscape of many global cities. In this context, municipalities have employed urban art as a tool to achieve certain objectives, of a cultural, economic or tourist nature. In this respect, one of the most used devices is that of urban art festivals, which are part of a broader process of cultural festivalization. In this article we will critically discuss this issue, starting from an extensive review of the literature and empirical data collected through various scientific projects, with particular emphasis on the Lisbon Metropolitan Area.

Keywords: cultural development; festivals; municipalities; public space.

\section{Pouvoir locale, art urbain et festivali- sation de la culture}

L'art urbain correspond à un mouvement artistique émergent qui transite entre l'espace médiatique, l'espace artistique et l'espace public urbain. La grande visibilité et le succès qu'il a acquis au cours des dernières années a généré un certain consensus quant à sa pertinence dans la ville contemporaine. L'art urbain est de plus en plus une présence constante dans le paysage des différentes villes du monde. Dans ce contexte, les mairies ont utilisé l'art urbain comme un outil pour atteindre certains objectifs de nature culturelle, économique et touristique. À cet égard, l'un des dispositifs les plus utilisés est celui des festivals d'art urbain, qui s'inscrivent dans un processus plus large de festivalisation de la culture. Dans cet article, nous discuterons cette question de façon critique, à partir d'un examen approfondi de la littérature et de données empiriques recueillies dans le cadre de divers projets scientifiques, en nous concentrant particulièrement sur la région métropolitaine de Lisbonne.

Mots-clés: développement culturel; festivals; espace public; municipalités. 
